Rev. Saúde públ., S. Paulo

$9: 263-8,1975$

\title{
ENSINAMENTO DE SANEAMENTO DO MEIO NAS ESCOLAS DE SAÚDE PÚBLICA *
}

Walter Engracia de Oliveira**

\begin{tabular}{c|c|}
\cline { 2 - 2 } & RSPU-B/266 \\
\hline
\end{tabular}

Oliveira, W.E. de - Ensino de saneamento do meio nas escolas de saúde pública. Rev. Saúde públ., S. Paulo, 9:263-8, 1975.

RESUMo: Após a última guerra mundial, e especialmente nesta década, em decorrência do crescimento demográfico e do desenvolvimento industrial, a par de migração da população rural em direção aos conglomerados urbanos, aumentaram os problemas relacionados ao saneamento do meio, devido a poluiçäo ambiental. Aumentou assim a necessidade de maior incremento ao ensino $e$ à pesquisa no campo do saneamento do meio, como também uma revisão dos programas. E evidenciado que o ensino do saneamento do meio deveria ser oferecido em todos os niveis do ensino, desde $\rho$ primário ao superior. Nas escolas de saúde pública, este ensino, tradicionalmente, é oferecido nos cursos de graduação, para graduados e pós-graduação (mestrado e doutorado), e em cursos de nivel médio. Algumas matérias do programa deveriam ser oferecidas em cursos curtos ou de especializacão. o programa de saneamento do meio, além de procurar dar uma formação geral no campo do saneamento ambiental, deve ser estabelecido em função das necessidades do pais, região ou Estado, o profissional que queremos preparar, e o papel da escola, isto é, o nivel de preparacão de pessoal - internacional, nacional, para um ou vários estados, deve influenciar o programa de saneamento do meio. Ponderou-se que as pesquisas sobre essa matéria devem ser intensificadas, tanto nos paises em fase de desenvolvimento, como nos paises subdesenvolvidos, devendo ser preferencialmente de caráter aplicado e mais simples. $O$ intercâmbio com os paises mais adiantados poderia ser útil para ambos.

UnItermos: Saneamento do meio. Ensino. Escolas de Saúde Publica.

\section{N T R O D U C A O}

Saneamento do Meio, conforme conceito definido por um grupo de especialistas reunido pela Organização Mundial da Saúde, é o controle de todos os fatores do meio físjco do homem, que exercem ou podem exercer efeito deletério sobre seu bem estar físico, mental ou social.
Assinalamos que após a II Guerra Mundial, e particularmente na presente década, em decorrência do crescimento demográfico e do desenvolvimento industrial observados na maioria dos paises, acentuadamente em determinadas regióes, a par de migração da população rural em

* Elaborado com base no trabalho apresentado na "Macy Conference or Schools of Public Health in Latin America", realizada de 17 a 19-11-1974, em Medellin, Colombia, sob o patrocínio da "Josiah Macy, Jr. Foundation" de New York

* Da Disciplina de Saneamento do Meio do Departamento de Saúde Ambiental da Faculdade de Saúde Pública da USP - Av. Dr. Arnaldo, 715 - São Paulo, SP - Brasil 
OLIVEIRA. W.E. de - Ensino de saneamento do melo nas escolas de saúde pública Rer. saide píbl., S. Paulo, 9:263-8, 1975

direção aos conglomerados urhanos. aumentaram os prolilemas relacionados ao saneamento do meio. devido à poluição ambiental. principalmente do ar. água. solo. sem deixar de mencionar a poluição acústica e a risual. Aumentou assim. a nosso ver. a necessidade de major incremento ao ensino e pesquisa no campo do saneamento do meio. Por outro lado. reforçando ainda mais nosso ponto de rista. os problemas do saneamento ambiental no meio maral. particularmente nos paises suldesencolvidos t nos paises em fare de desenvolvimento. estão também rigindo maior atençãu. Ponderamos que o sancamento do meio te a Educação em Sáde Pública. com aposo na Epidemiofouja. constitum os ralures fundamentais para " destmolvimento. Vunca é demais repertir que as medidas de caráter presen-

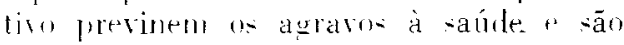
merlor rllstosas.

fim decorrencia dor asperlos assinalader. Iorma-se reecesaria uma revisão dos proserama- de saneamento do meio. prinripalmente comsiderando as novas técni-

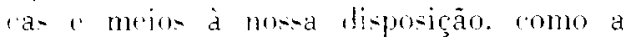
analjos de sisteman "as romputadores. () priprio ronceilo de aneamento do meio dese sofrer uma revião pois. além dos lateres dicelos e indiretos que podem influir no estade de salde do homem. deeriansos com-iderar on aspecetos econômien-linanceiros. pelos prejúzos decorrentes. prir exemplo. da poluçäo ambiental.

\section{NIVEIS DF, FNSINO DF SANFAIENTO DO}

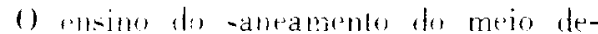
berid ser oferecheto em lodos niveis de ensino. deste " primário ao superior.

Vas erolas de Saúde Púlilica o ensino do santeamento do meio. tradicionalmente. é ofererido mes -teunites eursos:

- Cursor de Giaduação:

-- Cursos para Ciaduados ipara profi-somais já formados. romo médicos. enatmheiros. Hte.):
- Cursos de Pós-Craduação Mestrado * Doutoradol.

Assinalamos que nas escolas de Saude. Púllica que se dedicam também a ofrrecer cursos de nível médio. como a dr. Inspetores de Saneamento. o ensino d. Saneamento do Neio é também incluido nos programas dos Cursos.

A Disciplina de Saneamento do Mein. deve. a nosso ver. ser obrigatória em qualquer curso relacionado à Saúde Pílilica: é o que ocorre por exemplo nat Faculdade de Saúde Fública da L niversidade de São Paulo (FSP).

Ressaltamos a necessidade t" conveniên(ia de muitas matérias do programal de Saneamento do Meio serem também olirecidas através de cursos ('urtos. oul d. (ursos de especializaç̃o. para 1$)$ aptrfi-içoamento e/ou atualização de profi-cirnais diretamente ligados ou não à Saúle. Pública. Assim. por "xemplo. na Fl' temos ministrado cursos curtos sobre héduos Sólidos llixol + Limpeza Públira. destinados principalmente a engemheirm. hem como cursos de esperialização pala médicos do trahalho e engemheiros te - - yurrança do trahalho.

Assinalamos dois cursos que polterin ser ministrados em escolas de Saúde Púhica on mesmo em escolas esperializadas no preparo de pessoal de nível médio. - now quais dereria ser incluido um proerama em Santamento do Meio:

- Curso de Auxiliar de Saneamento 1 d. $l$ a :3 meses. () aluno deveria te a rurso primário rompleto. Sua lumçăo stria auxjliar o inspetor de saneamento on executar tarefas diver-at(o)mo o rociado.

-- Curso de Térnico de Santamento dit. 2 a 3 anos 1 . O aluno deveria ter eompletarto a l. ${ }^{2}$ fase do Curso serunditrio. ou seja 4 anos. segundo o si-trma educacional hrasileiro. Sua funcāo seria colahorar com o engenheim sanitarista. ou executar tarefas diver-as. inclusive como auxiliar do mérli- 
OLIVEIRA, W.E. de - Ensino de saneamento do meio nas escolas de saúde pública. Rer. Saude públ., S. Paulo, 9:263-8, 1975.

co-chefe de um Centro de Saúde, por exemplo. ou então operar instalações de tratame!to de água, ou de esgotos ou de lesíduos sólidos.

\section{PROGRAMAS DE SANEAMENTO DO MEIO}

O programa de Saneamento do Meio de um Curso, ou seja, as matérias contidas no mesmo, em primeira aproximação, além de procurar dar uma formação geral no campo do Saneamento Ambiental, deve ser estabelecido em função das necessidades do país, região ou estado; estas mesmas necessidades podem indicar a conveniência de certas matérias serem oferecidas também em cursos específicos, muitas vezes optativos. Assim, num país ou estado onde a malária constitui um problema, o controle de artrópodes deve ser mais enfatizado no curso ou mesmo ter um programa específico.

Na FSP, nos programas de saneamento do meio incluimos a matéria relacionada aos resíduos sólidos e limpeza, a qual também é objeto de um programa específico, oferecido aos engenheiros, e em nível de Pós-Graduação.

$O$ enfoque com que as matérias contidas no programa de Saneamento do Meio será tratado, é função do nível de ensino, mencionado no item anterior. Assim, ao tratar do abastecimento de água no meio rural, devemos enfatizar o problema dos detalhes técnicos da escolha do tipo de bomba a adotar, no caso do curso para engenheiros. ao passo que no curso para médicos, basta mencionar os tipos de bombas. $O$ enfoque das matérias vai assim depender também do tipo de profissional que pretendemos preparar.

A nosso ver, os programas da Disciplina de Saneamento do Meio e das disciplinas conexas, devem ser revistos com hase no acima exposto.

Outro aspecto ainda a considerar, o qual até um certo ponto é conseqüência do anterior, é o papel que uma determinada escola representa na conjuntura educacional; em outras palavras. uma escola pode se dedicar a preparar pessoal para um ou vários Estados, ou então. pode preparar pessoal em caráter nacional ou mesmo internacional. Assim, conforme o âmbito de preparação de pessoal, deverá ser estabelecido o programa do programa de Saneamento do Meio, e decidido quais cursos específicos relacionados ao Saneamento do Meio devem existir.

Como exemplo, citamos que na FSP. que recebe alunos de vários estados do país e do exterior, o programa de Saneamento do Meio é generalista, existindo vários programas específicos sobre Saúde Ocupacional, Poluição das Águas e do Ar. Biologia Sanitária, Saneamento e Planejamento Territorial, Resíduos Sólidos e Limpeza Pública e outros, permitindo a aluno aprofundar-se em determinadas matérias.

Apresentamos, em anexo, os programas resumidos das diversas disciplinas de Saneamento do Meio oferecidas nos cursos de graduação, para graduados e de pósgraduação, pela Faculdade de Saúde Pública da USP.

\section{PESQUISAS NO CAMPO DO SANEAMENTO DO MEIO}

As pesquisas no campo do Saneamento do Meio devem ser intensificadas. Ponderamos que, segundo nos parece, nos países em fase de desenvolvimento, bem como nos países subdesenvolvidos as pesquisas devem preferivelmente ser de caráter aplicado, sem entrar em problemas complexos, mas procurando pesquisar problemas aparentemente simples, mas cujas conclusões poderão redundar em grandes benefícios para a comunidade. Assim, por exemplo, pesquisas sobre filtros lentos. lagoas de oxidação, instalações simples de compostagem, instalações de recuperação de materiais dos resíduos sólidos e outros. O intercâmbio com países mais adiantados deve ser intensificado para aproveitarmos melhor a experiência dos mesmos; estes países poderão também usufruir o resultado das pesquisas realizadas entre nós. 
OLIVEIRA, W.E. de - Ensino de saneamento do meio nas escolas de saúde pública. Rev. Saúde públ., S. Paulo, 9:263-8, 1975.

CONCLUSAO

Os programas da disciplina de Saneamento do Meio das disciplinas conexas, devem ser revistos, em funçẫo das necessidades do país, região ou estado, consi- derando os cursos aos quais se destinam, e o profissional que se pretende preparar bem como o âmbito de atuação da escola-internacional, nacional, regional ou estadual.

OLIVEIRA, W.E. de - [Teaching environmental sanitation in schools of public health]. Rev. Saúde públ., S. Paulo, 9:263-8, 1975.

SUMmaRY: After the second world war, and specially in this decade, in consequence of population growth and industrial development, along with the rural migration in direction to urban areas the problems of environmental sanitation are increasing, including pollution control. It is necessary to increase and improve tuition and researches in the field of environmental sanitation, as well as review the programmes needed. Environmental sanitation must be teached from primary school to college. In the schools of Public Health usually it is ministered at the undergraduate level, in courses for students that have already concluded some undergraduate courses, and at the graduate level, as in programmes for ancillary personnel. Some aspects of environmental sanitation could be ministered in shorter specialization courses. The programme of environmental sanitation of any course must be oriented in order to give a broad knowledge in this field, and according to the needs of the country, region or state, and the professional we want to prepare; the role of the school, or, in other words, according to the level of preparation of personnel - International, National, Interstatal or Statal, must influence the programmes of environmental sanitation. Researches must be intensified. In the developed countries as in those undergoing development, the researches must be more practical and simple. Exchange with developed countries could be useful for both.

Uniterms: Sanitation, environmental. Teaching. Schools, Public Health. 
OLIVEIRA, W.E. de - Ensino de saneamento do melo nas escolas de saúde pública. Rev. Saúde públ., S. Paulo, 9:263-8, 1975.

\section{A N E X O}

PROGRAMAS DE SANEAMENTO DO MEIO

UNIVERSIDADE DE SAO PAULO - BRASIL FACULDADE DE SAUDE PUBLICA 1974

\section{Disciplina Fundamentos de Saneamento do Meio}

Oferecida nos cursos de graduação nutricionistas e enfermagem. Obrigatória.

Programa: Conceito de saúde, saúde pública e saneamento. Objetivos de saneamento do meio. Sistema de abastecimento de água potável no meio urbano, incluindo tratamento. Abastecimento de água no meio rural. Sistema de esgotos sanitários e pluviais, incluindo tratamento. Remoção e disposição de dejetos e esgotos no meio rural. Sistema de instalaçōes hidráulicas-sanitárias prediais. Acondicionamento, coleta, transporte, tratamento e/ou disposição final dos resíduos sólidos (lixo) e limpeza pública. Poluição das águas, ar e solo. Controle de artrópodes (moscas, mosquitos e baratas). Controle de roedores. Saneamento da habitação escolas. Saneamento de locais de recreaçáa: piscinas e outros. Saneamento de alimentos em geral. Saneamento em locais de produção, transporte, manipulação, armazenamento e distribuição de alimentos. Saneamento em situações de emergência: inundações, desastres em geral, acampamentos de obras ou de turismo, deslocamento de tropas, etc. $\mathrm{Pa}$ pel do saneamento do meio no processo de planejamento territorial.

Duração: 48 horas.

\section{Saneamento do Meio I}

Oferecida nos cursos para graduados - dentistas, educadores, enfermeiros, farmacêuticos-bioquímicos, médicos e veterinários. Obrigatória.

Programa: Introdução aos objetivos e importância do saneamento em saúde pú- blica. Sistemas de abastecimento de água potável e de águas residuárias no meio urbano. Abastecimento de água e disposição de dejetos e de águas residuárias no meio rural. Instalaçôes prediais de água e esgotos. Resíduos sólidos (lixo) e limpeza pública. Controle de artrópodes e roedores de importância em Saúde Pública. Controle da poluição ambiental água, ar e solo. Saneamento de edificações, de locais de recreação e de alimentos. Saneamento e planejamento. Saneamento em situações de emergência. Programa de Saneamento. Preparação de Pessoal.

Duração: 36 horas.

\section{Saneamento do Meio II}

Oferecida nos cursos para graduados - engenheiros e arquitetos (credenciada também para pós-graduação). Obrigatória.

Programa: Introdução aos objetivos e importância do saneamento em saúde pública. Aspectos sanitários dos sistemas de água e esgotos. Abastecimento de água no meio rural. Disposição de dejetos e de águas residuárias no meio rural. Aspectos sanitários das instalações prediais de água e esgotos e outras. Controle de artrópodes e de roedores de importância em saúde pública. Poluição ambiental água, ar, solo. Resíduos sólidos (lixo) e limpeza pública. Saneamento de edificações - habitação, hospitais e escolas. Saneamento de piscinas e de sistema de recreação. Saneamento de alimentos. Saneamento e planejamento. Saneamento em situações de emergência. Organização de Programas de Saneamento. Preparação de pessoal. Aspectos legais relacionados ao saneamento. Problemas sanitários nacionais e internacionais.

Duração: 96 horas.

\section{Saneamento do Meio III}

Oferecida nos cursos para graduados - engenheiros e arquitetos (credenciada também para pós-graduação). Optativa. 
OLIVEIRA, W.E. de - Ensino de saneamento do meio nas escolas de saúde pública Rer. Saúde públ., S. Paulo, 9:263-8, 1975.

Programa: Qualidade do meio em edificações: conforte térmico, acústico e visual. Problemas de isolamento, iluminação e ventilação nas edificações. Efeitos sobre a saúde; requisitos técnicos-sanitários e orientação heliotérmica e face a ventos. O problema de ruídos e seus efeitos sobre a saúde. Requisitos técnicos sanitários e legais e o conforto acústico nas edificações e no meio.

Duração: 48 horas.

\section{Saneamento do Meio e Hospital}

Oferecida nos cursos de administração hospitalar para graduados. Obrigatória.
Programa: Compreende o ensino de conhecimentos básicos de saneamento do meio com ênfase em problemas encontrados nos hospitais: Saneamento e saúde pública. Sistemas de abastecimento de água potável e de águas residuárias no meio urbano. Abastecimento de água e disposição de dejetos e de águas residuárias no meio rural. Instalações prediais de água e esgotos. Resíduos sólidos (lixo) e limpeza pública. Controle da poluição ambiental. Controle de artrópodes e roedores. Saneamento de alimentos. Saúde ocupacional. Saneamento de hospitais. Saneamento em situações de emergência.

Duração: 36 horas. 